\title{
Thermo-Gravimetric Analysis of Various Ratio of Blended Phenolic and Epoxy Composites
}

\author{
M. Asim, M. Jawaid, P. M Tahir, M. Nasir
}

\begin{abstract}
Present research deals with the various ratio $(0 \%$, $40 \%, 50 \%$, and $60 \%$ by $w t \%)$ of phenolic resin and epoxy resin blend composites. Phenolic resin/Epoxy resin blend composites were manufactured by hand lay-up technique and investigated the thermal properties (thermogravimetric analysis) of composites and evaluated optimum ratio of epoxy in phenolic composites. The residual content of pure phenolic was very high however the pure epoxy showed least thermal stable. After blending phenolic resin in epoxy resin, the thermal properties of epoxy/phenolic composite improved.
\end{abstract}

Keywords: Epoxy resin, Phenolic resin, Resin blend and Thermo-gravimetric analysis

\section{INTRODUCTION}

Thermoset polymers are known for its thermal resistance, mechanical properties and its durability, but these thermosets are expensive and have moderate production. The thermoset composites cannot reshaped, reformed or re-cured by using temperature, pressure and light irradiation after curing due to highly cross-linked web structure or it [1]. There are variety of thermoset such as melamine formaldehyde, urea formaldehyde, phenol formaldehyde, resorcinol formaldehyde, polyurethane, polyesters, and epoxy resin known for its high mechanical performance and thermal stability [2]. Among thermosets, phenolic resin is known for its industrial and commercial interest [3].

Phenolic resin is known as industrial material due to its high performances such as heat resistance, electrical insulator, flame resistant, and chemical resistant. Apart from the good qualities, phenolic resin has some issues such as in curing process, hexamethylenetetramine (hexamine) used as curing agent which is volatile and release water and/or ammonia compounds etc. due to condensation reaction [4]. These volatile compounds decline the mechanical properties of cured phenolic resin due to formation of micro-voids. Generally, Acid or based use as catalysts, resulted corrode equipment while processing. The cure phenolic is highly brittle material [5]. There were some researches based on the natural fibre reinforced phenolic composites, it revealed very

Revised Manuscript Received on July 22, 2019.

M. Asim*, Institute of Tropical Forestry and Forest Products (INTROP), Universiti Putra Malaysia, Serdang, Selangor, Malaysia

M. Jawaid*, Institute of Tropical Forestry and Forest Products (INTROP), Universiti Putra Malaysia, Serdang, Selangor, Malaysia

M.T. Paridah, Institute of Tropical Forestry and Forest Products (INTROP), Universiti Putra Malaysia, Serdang, Selangor, Malaysia

M. Nasir, Forest Products Utilization, college of forestry, Banda University of Agriculture and Technology, Banda, India attractive mechanical, tribological, thermal and fire retardant properties [6-9]

Epoxy resin is the combination of prepolymer and hardener system. The prepolymer is low molecular weight oligomer which carry more epoxy groups per molecule [10]. The characteristics of epoxy is identified through three types of rings; epoxide, oxirane, glycidyl or ethoxyline group. These epoxy resin crosslinked through a polymerization reaction with a hardener at normal room temperature or at elevated temperatures [11]. In innovation of new composite materials and technologies, civil and structural engineering have been developed new polymers and additives by blending different types of polymers [12].

In this research, phenolic resin and epoxy resin are blend in various ratio to find the new characteristics of new composites. The thermogravimetric analysis was conducted to study the thermal stability of blended polymers composites.

\section{MATERIALS AND METHOD}

\section{A. Materials}

Novolac type Phenolic formaldehyde resin (Grade PH-4055) was supplied by Chemovate Girinagar, Banglore, India. Epoxy resin was bought from Epochemie, singopore. Properties of phenolic resin and epoxy resin are shown in Table I.

Table I: Properties of epoxy and Phenolic resin [7].

\begin{tabular}{|c|c|c|c|}
\hline Epoxy & Descriptions & $P F$ & Descriptions \\
\hline $\begin{array}{l}\text { Amine value (mg } \\
\mathrm{KOH} / \mathrm{g})\end{array}$ & $300 \sim 20$ & $\begin{array}{l}\text { Physical } \\
\text { state }\end{array}$ & Powder \\
\hline $\begin{array}{l}\text { Viscosity (BH type } \\
@ 25^{\circ} \mathrm{C} \text {, cPs }\end{array}$ & $200 \sim 400$ & Colour & $\begin{array}{l}\text { Pale yellow } \\
\text { colour }\end{array}$ \\
\hline Color (Gardner) & $<2$ & Free phenol & $<1 \%$ strictly \\
\hline $\begin{array}{l}\text { Pot life (100g } \\
@ 25^{\circ} \mathrm{C}\end{array}$ & $75 \mathrm{~min}$ & $\mathrm{pH}$ & $8-8.5$ \\
\hline \multirow{3}{*}{$\begin{array}{l}\text { Thin film set time } \\
\left(@ 25^{\circ} \mathrm{C}\right)\end{array}$} & $5 \mathrm{hrs}$ & Density & 1.28 \\
\hline & & $\begin{array}{l}\text { Melting } \\
\text { point }\end{array}$ & $70-73{ }^{\circ} \mathrm{C}$ \\
\hline & & Curing time & $45 \mathrm{sec}$ to $95 \mathrm{~min}$ \\
\hline
\end{tabular}




\section{B. Fabrication of composites}

Epoxy resin and phenolic resin were mixed in various ratios properly, then hardener was added (Epoxy: Hardener : $2: 1)$. The blended polymers were poured in $15 \times 15 \times 3 \mathrm{~mm}$ stainless metal plate. The $3 \mathrm{~mm}$ stainless steel plate was placed into hydraulic pressure hot press at $160^{\circ} \mathrm{C}$. The stainless metal plate was removed from the press after 6 min and kept for cooling on room temperature, and then samples were cut for testing according to ASTM standard. The formulations of composites are described in Table II.

Table II: Formulations of composites

\begin{tabular}{lll}
\hline $\begin{array}{l}\text { Type of composites } \\
\text { and } \\
\text { hybrid composites }\end{array}$ & Epoxy (wt\%) & PF (wt\%) \\
\hline Pure Epoxy & 100 & 0 \\
6Epoxy4PF & 60 & 40 \\
1Epoxy1PF & 50 & 50 \\
4Epoxy6PF & 40 & 60 \\
Pure PF & 0 & 100 \\
\hline
\end{tabular}

\section{Thermogravimetric Analysis}

The thermal stability of PF and Epoxy resin blend composites was characterized using a thermo-gravimetric analyzer (TGA Q 500 TA Instrument, The United States), at a heating rate of $20^{\circ} \mathrm{C} / \mathrm{min}$ in the range from $030^{\circ} \mathrm{C}$ to $700^{\circ} \mathrm{C}$.

\section{RESULTS AND DISCUSSION}

The thermographs of pure PF pure epoxy resin and PF/epoxy blend composite are shown in Fig. 1. In the case of polymer composites, the first weight loss between 60 and $100^{\circ} \mathrm{C}$ corresponds to water vaporization in all composite samples. There is no weight loss at $100^{\circ} \mathrm{C}$, due to the absence of water molecule in the pure PF sample [13]. Pure phenolic exhibited $32.16 \%$ single weight loss at $420.73{ }^{\circ} \mathrm{C}$, and the final char content was $55.97 \%$ resulted from the increasing of char constituent [14]. The thermal decomposition were related to the phenolic groups adjacent to the methylene bridges, and the numbers of dihydroxy phenyl methane units [15].

TGA results are summarized in Table III for pure phenolic matrix, pure epoxy and PF/Epoxy blend composites and show the first and second weight loss in all types of composites.

Table III: Thermogravimetric analysis results of PF, Epoxy and its blended composites.

\begin{tabular}{llll}
\hline Composite & Initial-degrada & Final-degrada & \multicolumn{1}{c}{ Resid } \\
$s$ & tion temperature & tion temperature & ual \\
& and weight loss & and weight loss & mass
\end{tabular}

\begin{tabular}{|c|c|c|c|c|c|}
\hline & ${ }^{\circ} \mathrm{C}$ & $\%$ & ${ }^{\circ} \mathrm{C}$ & $\%$ & $\%$ \\
\hline Pure Epoxy & - & - & 358.21 & 83.73 & 6.229 \\
\hline 6Ероху4PF & 115.2 & 5.8 & 279.04 & 43.16 & 30.57 \\
\hline & 6 & 4 & & & \\
\hline 1Epoxy1PF & 110.4 & 6.0 & 288.55 & 48.16 & 30.12 \\
\hline & 3 & 4 & & & \\
\hline 4Ероху6РF & 118.5 & 5.5 & 284.34 & 49.16 & 29.72 \\
\hline & 9 & 4 & & & \\
\hline Pure PF & - & - & 420.73 & 32.16 & 55.97 \\
\hline
\end{tabular}

Initially pure epoxy and blended composites have shown weight loss between $100-200^{\circ} \mathrm{C}$, it showed epoxy resin has some free hydroxyl molecules and dehydration of secondary alcoholic groups and evaporation of physically weak and loosely bound moisture on the surfaces of the composites [16]. The thermal degradation of pure epoxy was observed above $300^{\circ} \mathrm{C}$, the decomposition of pure epoxy was due to the pyrolysis and decomposition of aromatic groups of the epoxy network and the degradation of aliphatic amine curing agent owing to low breaking energy of $\mathrm{C} \mathrm{N}$ bond, as reported by other findings [17, 18].

All blended composites showed thermal degradation between $100-150^{\circ} \mathrm{C}$, due to dehydration process and weight loss was measured between $5.54-6.04 \%$ that is very less. The final degradation temperatures of blended composites were between $279.04^{\circ} \mathrm{C}$ to $288.55^{\circ} \mathrm{C}$ that is lower than pure epoxy and pure PF but the weight loss was very lower comparative to pure epoxy. The final remaining residue of blended composites showed more $500 \%$ more than pure epoxy. 


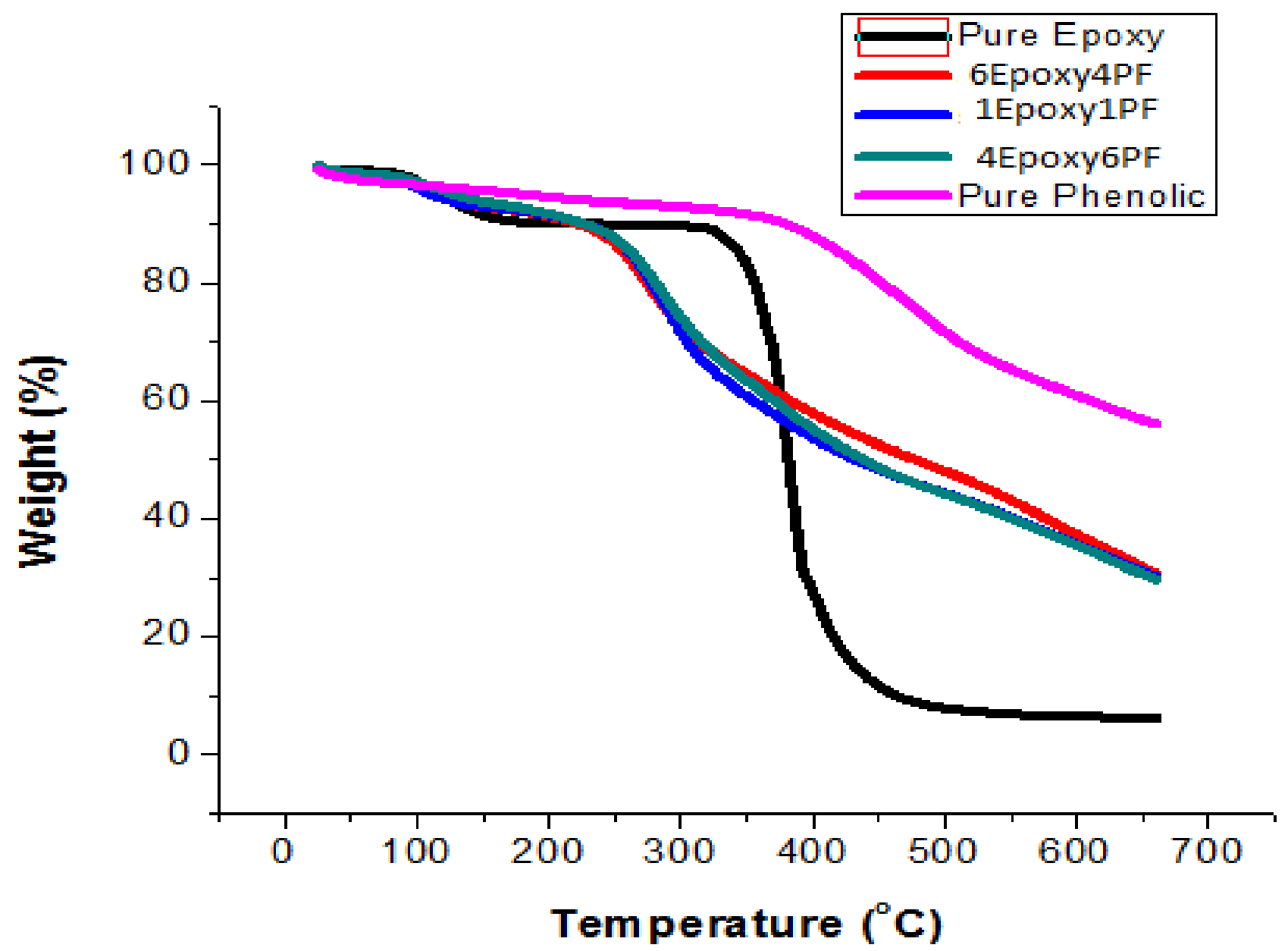

Fig. 1. TGA curve of PF and Epoxy resin blend composites

The Derivative thermogravimetric (DTG) thermograph showed the derivative weight loss curve used to indicate the point of weight loss. DTG curved showed pure epoxy started weight loss after $300^{\circ} \mathrm{C}$ but the percentage of weight loss per min was too high shown in Fig. 2.

\section{CONCLUSION}

In this research, various ratio of blended PF and epoxy resin are discussed the thermal properties or its effects. PF is highly thermal stable polymer and epoxy resin is also thermally stable but after the blend the temperature of thermal stability is reduced it may be due to the poor crosslinking between PF and epoxy. The blended composites showed lower thermally stable, but weight loss percentage were also very low compare to pure epoxy. Final residues of blended composite are very high in compare to the pure epoxy. 


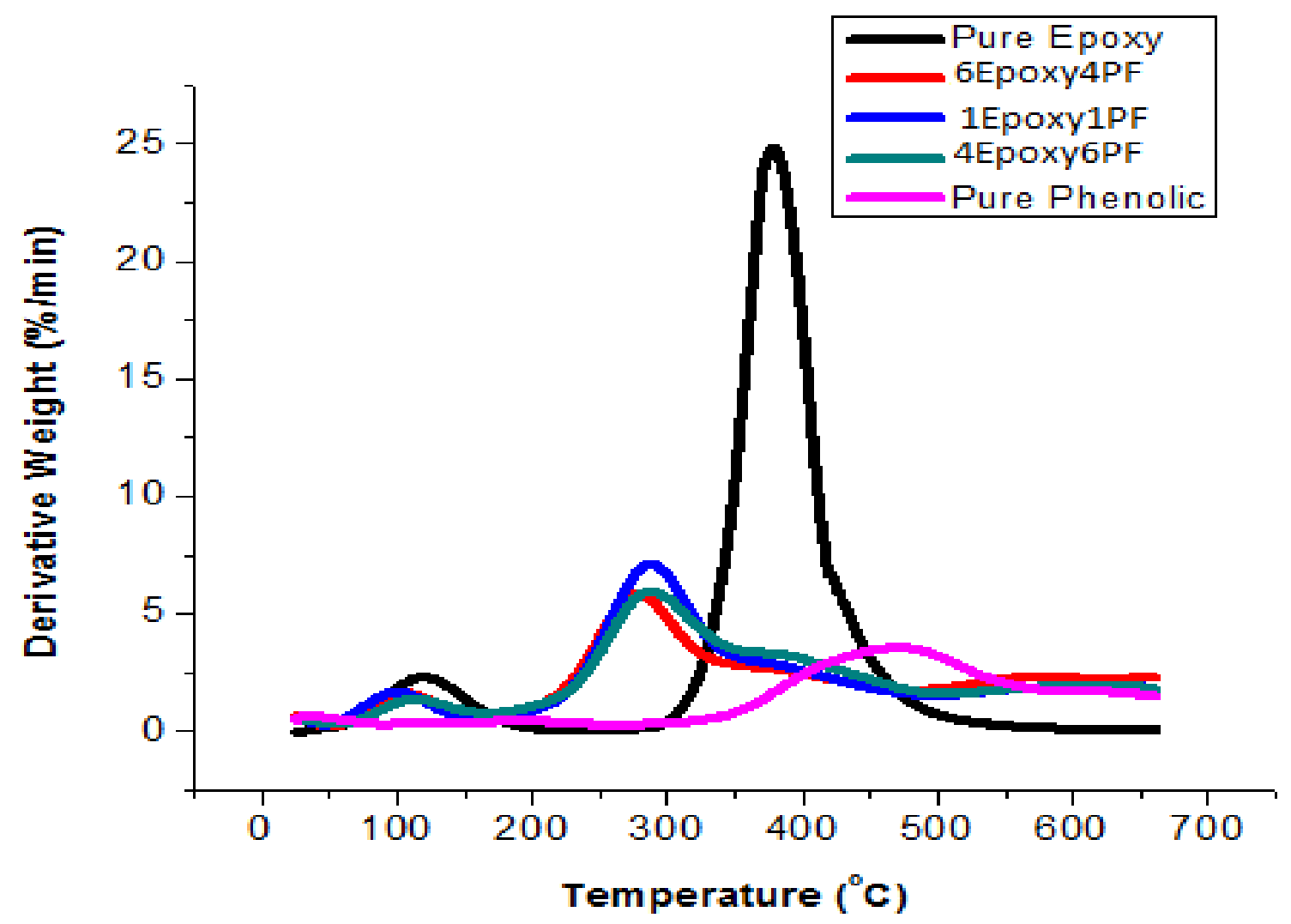

Fig. 2. DTG curve of PF and Epoxy resin blend composites

\section{ACKNOWLEDGMENT}

The authors would like to express their gratitude and sincere appreciation to the Department of biocomposite and technology, Institute of tropical forestry and forest products (INTROP), Universiti Putra Malaysia for their scientific assistance and support to help accomplish this study.

\section{REFERENCES}

1. J.-M. Raquez, M. Deléglise, M.-F. Lacrampe, P. Krawczak, "Thermosetting (bio) materials derived from renewable resources: a critical review," Prog. Polym. sci., 35, 2010, 487-509.

2. E. Vivaldo-Lima, E. Saldívar-Guerra, Handbook of polymer synthesis, characterization, and processing, Wiley Online Library2013.

3. M. Asim, N. Saba, M. Jawaid, M. Nasir, M. Pervaiz, O.Y. Alothman, "A review on phenolic resin and its composites," Curr. Anal. Chem., 14, 2018, 185-197.

4. M. Nasir, D. Khali, M. Jawaid, P. Tahir, R. Siakeng, M. Asim, T. Khan, "Recent development in binderless fiber-board fabrication from agricultural residues: A review," Constr. Build. Mater., 211, 2019, 502-516.

5. H. Kimura, A. Matsumoto, K. Ohtsuka, "Studies on new type of phenolic resin-Curing reaction of bisphenol-A-based benzoxazine with epoxy resin using latent curing agent and the properties of the cured resin,” J. appl. Polym. Sci., 109, 2008, 1248-1256.

6. S. Balaji and M. A. N. AB, "Tribological performance of graphene/graphite filled phenolic composites-A comparative study." Compos. Commun., 15, 2019, 34-39.

7. M. Asim, M. Jawaid, M.T. Paridah, N. Saba, M. Nasir, R.M. Shahroze, "Dynamic and Thermo-Mechanical Properties of Hybridized Kenaf/PALF Reinforced Phenolic Composites," Polym. Compos., 40, 2019, 3814-3822.
8. J. Ding, J. Sun, Z. Huang, and Y. Wang, "Improved high-temperature mechanical property of carbon-phenolic composites by introducing titanium diboride particles" Composites Part B, 157, 2019, 28.

9. M. Asim, M. Jawaid, K. Abdan, M. Ishak, and O. Alothman, "Effect of hybridization on the mechanical properties of pineapple leaf fiber/kenaf phenolic hybrid composites" J. Renew. Mater, 6, 2018, 38.

10. Y. Zhang, K.Y. Rhee, D. Hui, S.-J. Park, "A critical review of nanodiamond based nanocomposites: Synthesis, properties and applications," Composites Part B, 143, 2018, 19-27.

11. A.A. Azeez, K.Y. Rhee, S.J. Park, D. Hui, "Epoxy clay nanocomposites-processing, properties and applications: A review," Composites Part B, 1, 2013, 308-320.

12. J.-C. Munoz, H. Ku, F. Cardona, D. Rogers, "Effects of catalysts and post-curing conditions in the polymer network of epoxy and phenolic resins: Preliminary results," J. Mater. Process. Technol., 202, 2008, 486-492.

13. M. Asim, M. Jawaid, M. Nasir, N. Saba, "Effect of fiber loadings and treatment on dynamic mechanical, thermal and flammability properties of pineapple leaf fiber and kenaf phenolic composites," J. Renew. Mater., 6, 2018, 383-393.

14. M. Asim, M. Paridah, N. Saba, M. Jawaid, O.Y. Alothman, M. Nasir, Z. Almutairi, "Thermal, physical properties and flammability of silane treated kenaf/pineapple leaf fibres phenolic hybrid composites," Compos. Struct., 202, 2018, 1330-1338.

15. Y.K. Lee, D.J. Kim, H.J. Kim, T.S. Hwang, M. Rafailovich, J. Sokolov, "Activation energy and curing behavior of resol-and novolac-type phenolic resins by differential scanning calorimetry and thermogravimetric analysis," J. Appl. Polym. Sci., 89, 2003, 2589-2596.

16. N. Saba, A. Safwan, M. Sanyang, F. Mohammad, M. Pervaiz, M Jawaid, O. Alothman, M. Sain, "Thermal and dynamic mechanical properties of cellulose nanofibers reinforced epoxy composites," Int. j. biol. macromol., 102, 2017, 822-828.

17. G.-m. Wu, D. Liu, G.-f. Liu, J. Chen, S.-p. Huo, Z.-w. Kong, "Thermoset nanocomposites from waterborne bio-based epoxy resin and cellulose nanowhiskers," Carbohydr. Polym., 127, 2015. 
18. A. Sen, S. Kumar, "Coir-fiber-based fire retardant nano filler for epoxy composites," J. Therm. Anal. Calorim., 101, 2010, 265-271.

\section{AUTHORS PROFILE}

M. Asim is Post-Doctoral fellow in Institute of

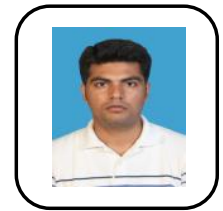
Tropical Forestry and Forest Products (INTROP), University Putra Malaysia. His area of expertise is polymer composites. He has published 35 articles in international journals, book chapters and proceedings

M. Jawaid is currently working as Fellow Researcher at Institute of Tropical Forestry and Forest Products (INTROP), Universiti Putra Malaysia. His area of expertise is polymer science. he has published 8 books, 25 book chapters, and more than 250 International journal papers.

Paridah Md Tahir is a professor in Institute of Tropical Forestry and Forest Products (INTROP), University Putra Malaysia. Her area of expertise is Wood Chemistry. She has published more than 250 articles in numerous journals, co-authored 6 books and more than 100 chapters in book, proceedings, technical and consultation reports.

M. Nasir is assistant professor in college of forestry, Banda University of Agriculture and Technology, Banda, India. His area of expertise is wood science and technology. He has published 40 articles in international journals, book chapters and proceedings. 